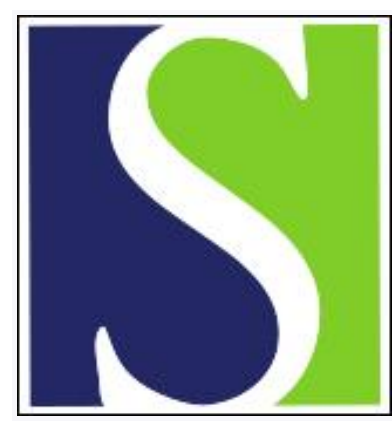

Scand J Work Environ Health 2007;33(4):241-243

https://doi.org/10.5271/sjweh.1138

Issue date: 31 Aug 2007

\title{
Focus and future of occupational health journals
}

by Viikari-Juntura $E$, Burdorf $A$

Affiliation: Scandinavian Journal of Work, Environment \& Health, Topeliuksenkatu 41 a A, Fl-00250 Helsinki, Finland. eira.viikari-juntura@ttl.fi

Refers to the following texts of the Journal: 2007;33(4):245-251 2004;30(3):223-233 2007;33(4):318-319 2007;33(2):81-83 2006;32(1):1-4 2005;31(4):249-257

Key terms: editorial; occupational health journal

This article in PubMed: www.ncbi.nlm.nih.gov/pubmed/17717614 


\section{Focus and future of occupational health journals}

Occupational medicine and occupational health are well-established research areas in various scientific journals with a longstanding tradition. Bibliometric methods can be used to identify the papers that have had a large impact on research. One metric for measuring this impact is the number of citations an article receives over time. Although this metric has attracted severe criticism, it is one of the few available metrics that allows a comparison across journals and research areas. An example of a bibliometric analysis is the paper "Citation Classics in Occupational Medicine Journals" by Gehanno et al in this issue of the Scandinavian Journal of Work, Environment \& Health (1). These authors reviewed five occupational medicine journals with the highest impact factor in the field to find citation classics for the period 1949-2005 (ie, papers that have been cited at least 100 times in the scientific literature). They found 85 such papers and calculated that, between $0 \%$ and $1.02 \%$ of published papers in the five journals became a citation classic. The Scandinavian Journal of Work, Environment \& Health did well in this respect, representing the highest value. Although the, by far, most-cited paper originated from 1960, most citation classics were published in the 1980s and 1990s. The United Kingdom was the prime producer of citation classics in earlier decades, partly due to the fact that the British Journal of Industrial Medicine commenced publication in 1949. Journals in other countries emerged from 1971 through 1980, and the balance shifted towards North America, Scandinavia, and the Netherlands in the later decades.

An earlier bibliometric study, covering publications in eight occupational health journals in the period 1992-2001, reported that North America (40\%), the United Kingdom (9\%), and Sweden (9\%) were the countries with the highest contribution to the total scientific production (2). The most recent evaluation analyzed papers and their citations in the "top 10" occupational health, work environment, or ergonomics journals during 2001-2005 (3). North America and Europe had produced the majority of published papers in these journals. When adjusted for general population size, the Scandinavian countries and the Netherlands were the most productive countries regarding occupational health journals, and Sweden, the Netherlands, the United Kingdom, and Finland were the most productive regarding ergonomics journals. The citation rates per paper were, however, relatively low, ranging across countries between 2.1 to 3.7 citations per article over a period of 5 years (3).

Recently, we analyzed how papers published in the Scandinavian Journal of Work Environment \& Health were cited in the shorter and longer run (4). Musculoskeletal disorders, psychosocial factors, and occupational epidemiology were the major research areas. The first two also made a larger contribution to the citations than their proportion in the papers would have predicted. A closer look at inequalities in the citation rate of articles published in 2004 showed that citations to individual papers were extremely unevenly distributed, with one paper contributing $23 \%$ of all citations and the bottom $80 \%$ of the articles combined contributing about $40 \%$ of all citations. A further analysis covering the period of 1997-2006, in which we looked at the average citation rate per year, showed 6 papers with an annual citation rate of 10 or higher and 21 papers averaging between 5 to 10 citations per year. A substantial proportion of these papers will become a citation classic in the next 5 years.

Reviews were cited more frequently than original papers, which may be a disappointing message for researchers who have painstakingly carried out the original studies included in these reviews. Reviews have become an important form of data synthesis with their own methods, such as the systematic review and meta-analysis (5). Contrary to earlier times, reviews are nowadays accepted in some countries as papers that make up a doctoral thesis, and making a review could indeed be a useful way for a talented 
doctoral student to become familiar with his or her research area. Well-done reviews could even serve as tutorial material, expanding the readership of occupational medicine or health journals.

\section{Shifts in the focus of occupational health research}

The review on citation classics by Gehanno et al (1) showed that asbestos, lead, and pesticides are truly classic occupational health issues. Solvents became an important topic during the 1970s and 1980s, and the area of musculoskeletal disorders emerged in the 1980s and increased markedly in the 1990s. Our own analysis of the Scandinavian Journal of Work Environment \& Health demonstrated that psychosocial factors emerged as a frequently cited topic in addition to musculoskeletal disorders in the 1990s. Both topics are also widely studied in adjacent areas in public health and general medicine, and, as a consequence, articles have a higher probability of picking up citations.

Workplace exposures play a major role for a range of disorders, and, consequently, it should be possible to reduce the incidence of these disorders by targeting appropriate interventions towards work-related factors. The paucity of intervention studies in the most cited papers in the analysis of Gehanno et al (1) and Burdorf \& Viikari-Juntura (4) is striking and should be taken as a challenge by researchers in the field. There is an urgent need for studies that look at the feasibility, effectiveness, and costs and benefits of interventions at the workplace or in occupational health service settings $(6,7)$.

\section{Where should researchers in occupational medicine publish their work?}

The impact factor, a measure of the average citation rate over a 2-year period, is an important characteristic of a journal and perhaps the most decisive for the number and quality of papers that are being submitted. It is an interesting observation that the strongest predictor of citations per year for a particular article is the impact factor of the publishing journal, reflecting the tendency among authors themselves to put more value on the publishing journal than on the traditional measures of study quality (8). Another intriguing observation is that the average impact factor among the top five journals in public health has doubled over the past 20 years from 2 to 4 , whereas the top journals in occupational health improved from 1.1 to 1.6 (9). Thus other journals seem to have increased their impact factor more rapidly than occupational health journals, and this circumstance may prompt prospective authors to make other journals their first choice for submission.

The standing of a journal also has an impact on deciding the ranking of scientists for academic positions. A recent development is that, through available databases, such as the ISI Web of Knowledge or Google Scholar, the focus has shifted towards the numbers of citations for particular papers of individual scientists. Metrics, such as the Hirsch Index, have been developed to summarize the number of citations and number of papers of an individual author into one figure (10).

Since the impact factor and citations have become important drivers in decisions concerning the selection of scientific journals for submission, journals are considering ways to improve, for example, by speeding the processing of manuscripts and increasing the accessibility to papers. Some journals publish papers as "online first" on their internet site as an unedited version after acceptance. This process adds the months between the "online first" publication day and the appearance of the printed or online version to the paper's "exposure time" for citations. Another development is the open access approach, whereby accessibility no longer depends on subscription to the journal. Some attempts have been made in areas other than occupational health to assess the difference that improved accessibility may have on the citation rate. It has been seen that, in some areas, the most prominent and citable authors are more likely to make their papers available in the open access model. When controlled for this selection bias and early view possibility that "online first" offers, there seems to be little or no effect of open access per se on citations. It should be noted, however, that the effect may not be similar in different scientific areas (11). 
The analyses of Gehanno et al (1), as well as our own (4), show that the role of occupational health journals is limited in the scientific literature. In journals such as the Scandinavian Journal of Work, Environment \& Health and the Occupational and Environmental Medicine, one or two papers per year will, with time, become a citation classic. Comparable analyses have not been made for occupational health papers published in public health, epidemiology, or general medical journals. What message should a researcher in this area take home? Should one continue to publish in occupational medicine journals or should one strive for the higher-impact general medical or epidemiology journals? There seems to be no absolute hindrance for a paper published in an occupational health journal to be highly cited, as is demonstrated by Gehanno et al (1). One should attempt to publish in a journal that will attract the potential readers. This journal may not be the one with the highest citation rate. Occupational health journals have a wide readership also among practitioners, who-unlike researchers in the field—are not likely to cite an article in a scientific paper, but may, instead, apply the information in practice. This possibility may result in a societal impact of research that should be more appreciated than receiving many citations is.

\section{References}

1. Gehanno JF, Takahashi K, Darmoni S, Weber J. Citation classics in ocupational medicine journals. Scand J Work Environ Health. 2007;33(4):245-51.

2. Navarro A, Martin M. Scientific production and international collaboration in occupational health, 1992-2001. Scand J Work Environ Health. 2004;30(3):223-33.

3. Wegman D, Burdorf A, Oldershaw P, Schulte-Fortkamp, Viikari-Juntura E. International evaluation of Swedish work environment research. Stockholm: Swedish Council for Working Life and Social Research (FAS); 2006.

4. Burdorf A, Viikari-Juntura E. Bibliometric analysis of the Scandinavian Journal of Work, Environment \& Health: results from the past 10 years. Scand J Work Environ Health. 2007;33(4):318-9.

5. Verbeek J. More systematic reviews needed to improve occupational health [editorial]. Scand J Work Environ Health. 2007;33(2):81-3.

6. Leigh JP Expanding research on the economics of occupational health [editorial]. Scand J Work Environ Health. 2006;32(1):1-4.

7. Hlobil H, Staal JB, Spoelstra M, Ariëns GA, Smid T, van Mechelen W. Effectiveness of a return-to-work intervention for subacute low-back pain [review]. Scand J Work Environ Health. 2005;31(4):249-57.

8. Callaham M, Wears RL, Weber E. Journal prestige, publication bias, and other characteristics associated with citation of published studies in peer-reviewed journals. JAMA. 2002;287:2847-50.

9. Porta M, Copete JL, Fernandez E, Alguacil J, Murillo J. Mixing journal, article, and author citation, and other pitfalls in the bibliographic impact facto. Cad Saude Publica 2003;19:1947-62.

10. Hirsch JE. An index to quantify an individual's scientific research output. Proc Natl Acad Sci USA. 2005;102:16569-72.

11. Craig ID, Plume AM, McVeigh ME, Pringle J, Amin M. Do open access articles have greater citation impact? A critical review of the literature. Publishing Research Consortium; 2007 [cited 31 July 2007]. Available from: http://www.publishingresearch.net/Citations.htm.

Scandinavian Journal of Work, Environment \& Health

Eira Viikari-Juntura, Assistant Editor-in-Chief

[E-mail: eira.viikari-juntura@ttl.fi]

Alex Burdorf, Associate Editor

[E-mail: a.burdorf@erasmusmc.nl] 
